\title{
O Efeito da Coerência e da Complexidade de Relógios de Pulso Esportivos sobre a Agradabilidade Percebida
}

\author{
The Effect of the Coherence and Complexity of Sports Wristwatches on Perceived \\ Pleasantness
}

SILVA, Renan Cruz da; Mestrando em Design; PPGDESIGN / Universidade Federal de Pernambuco renan.cruz01@gmail.com

COSTA FILHO, Lourival; Doutor em Desenvolvimento Urbano; Universidade Federal de Pernambuco lourivalcosta@yahoo.com

\section{Resumo}

Este artigo apresenta uma pesquisa que escolheu duas características de relógios de pulso esportivos para estudo - coerência e complexidade - com o objetivo de prover informações empíricas sobre a agradabilidade percebida. Foi utilizada uma sentença estruturadora geral, procedimento básico da Teoria das Facetas, para estruturar a investigação empírica, que optou pelo questionário online para coletar os dados, interpretados através de uma tabela de distribuição das frequências. Diante dos resultados da pesquisa, concluiu-se que os participantes preferem relógios com baixo contraste e mínima complexidade visual.

Palavras Chave: agradabilidade percebida; estética do produto; relógio de pulso.

\begin{abstract}
This article presents a research that chose two characteristics of sports wristwatches for study - coherence and complexity - in order to provide empirical information on the perceived pleasantness. A general mapping sentence, basic tool of Facet Theory, was used to structure the empirical investigation, which chose the online questionnaire to collect the data, interpreted through a frequency distribution table. In the light of the results of the research, it was concluded that participants prefer low-contrast and minimum complexity watches.
\end{abstract}

Keywords: perceived pleasantness; product aesthetic; wristwatch. 


\section{Introdução}

Ao se referir à atual posição do relógio de pulso dentro da sociedade de consumo, é importante considerar que ela difere substancialmente em comparação a época em que os primeiros modelos foram criados. Eles foram durante muito tempo objetos de uso sóbrio, cuja configuração era baseada na funcionalidade de leitura pelo olho humano. Hoje, muitos relógios foram convertidos em elementos de moda, com pulseiras de couro perfurado, correntes metálicas, mostradores coloridos, números floreados, etc. que tentam satisfazer aos desejos individuais dos consumidores (LÖBACH, 2001).

Em paralelo, observa-se o crescente aumento no número de corredores de rua no Brasil. Segundo o jornal O Globo (2015), a massificação nas corridas de rua no país ocorre por diferentes motivos: enquanto no passado as pessoas corriam visando a melhoria da sua performance, hoje em dia fatores como saúde, qualidade de vida e socialização vêm ganhando destaque. Em consequência, o mercado relacionado a esse cenário também vem crescendo, e diferentes empresas procuram fazer com que seus produtos sejam a preferência dos atletas, inclusive àquelas que projetam relógios de pulso.

Norman (2004) diz que produtos podem ser mais do que a soma das funções que eles desempenham (nesse caso, dizer as horas). Seu valor real pode ser satisfazer as necessidades emocionais das pessoas, e uma das mais importantes de todas as necessidades é demonstrar a autoimagem do indivíduo, seu lugar no mundo. De acordo com Löbach (op. cit), essas inter-relações entre usuários e produtos compõem um processo que pode ser denominado de comunicação estética, em que o designer industrial é o emissor de uma mensagem em forma de um produto (produção estética ou processo de design) e o usuário é o receptor da mensagem estética contida nele (consumo estético ou processo de uso).

Considerando o que foi apresentado sobre o processo de comunicação estética, o presente artigo tem por objetivo prover informações empíricas sobre a agradabilidade percebida em relógios de pulso esportivos sob a ótica de corredores de rua.

A agradabilidade percebida é uma construção psicológica, pois envolve julgamentos subjetivos. Esses julgamentos consideram referências do produto ou dos sentimentos das pessoas sobre o produto. Os primeiros são chamados de julgamentos perceptuais/cognitivos e os segundos de julgamentos afetivos. Embora a agradabilidade percebida possa depender, em parte, de fatores perceptuais/cognitivos, é, por definição, um julgamento emocional que envolve avaliação e sentimentos. Como resultado, a agradabilidade percebida foi medida nesta pesquisa através de julgamentos avaliativos para relógios de pulso esportivos com diversas qualidades estéticas.

Como suporte para a investigação empírica desta pesquisa, foi adotada uma sentença estruturadora geral, instrumento básico da Teoria das Facetas, e utilizado o questionário online (criado através do aplicativo Formulário Google), baseado no Sistema de Classificações Múltiplas, para a coleta dos dados. Por fim, a interpretação desses dados foi realizada mediante a utilização de uma tabela de distribuição das frequências.

\section{Considerações Teóricas}

Este tópico apresenta as principais bases teóricas utilizadas para o fomento da pesquisa empírica. Na medida em que o foco do trabalho é a avaliação estética de produtos, optou-se pelo 
enfoque da avaliação afetiva (RUSSEL, 1988) e o conceito de qualidade visual percebida (NASAR, 2008) como fonte de referência para a avaliação proposta.

A respeito das avaliações afetivas, Russel (1988) define a agradabilidade como uma dimensão que, em conjunto com outras de caráter similar (estímulo, calma, emoção, entre outras), é resultado de julgamentos cognitivos e de julgamentos emocionais, sendo o primeiro relacionado a como um indivíduo interpreta algo e o segundo relacionado aos sentimentos afetivos sobre isso. Em suma, agradabilidade é uma das possibilidades de interpretação da coisa observada.

Avaliações afetivas ocorrem mediante categorias de preferência visual. Duas delas foram escolhidas para estudo nesta pesquisa - complexidade e coerência - sendo esta última obtida através da redução do contraste entre os elementos do entorno humano. O entorno humano, formado principalmente por objetos arquitetônicos e produtos industriais, segundo aponta Kaplan (1988), deve ser "envolvente" para atrair a atenção humana, assim como "fazer sentido" para ser compreendido. A complexidade e a coerência, ainda para o mesmo autor, desempenham papéis importantes na satisfação dessas duas necessidades humanas.

Costa Filho et. al. (2016) cita que, de acordo com Berlyne (1972) e Wohlwill (1976), a complexidade gera incerteza e também provoca o envolvimento do indivíduo. Pouca complexidade é monótona e cansativa, enquanto o excesso é caótico e estressante. Para a agradabilidade percebida, o nível intermediário de complexidade do entorno, presumivelmente, seria o ideal.

Já a coerência, segundo Kaplan (op. cit.), é o componente responsável pelo fazer sentido, por meio da organização dos elementos. Isso contribui para a redução da incerteza e o aumento do tom hedônico (agradabilidade ou beleza). Entre as medidas que podem ser tomadas para o aumento da coerência, a variação de contraste é uma das mais importantes. Quando há baixo contraste entre os elementos, aquilo que é mais importante no entorno é favorecido. $O$ excesso transmite incerteza e insegurança aos usuários. Por isso, o contraste foi escolhido para estudo nesta pesquisa.

Segundo Nasar (2008), a agradabilidade percebida deve ser elevada para moderada complexidade e alta coerência. Para se obter alta coerência, é necessário haver baixo contraste entre os elementos estéticos. Nesta pesquisa, esse postulado teórico foi adotado para a avaliação da agradabilidade percebida em relógios de pulso esportivos, objeto de estudo empírico escolhido.

\section{Considerações Metodológicas}

Conforme citado, foi utilizada uma sentença estruturadora geral, instrumento básico da Teoria das Facetas, para a estruturação da investigação empírica. Essa sentença é a responsável por apresentar de forma resumida todo o delineamento das facetas que definem uma pesquisa específica. Sua leitura é feita da esquerda para a direita, envolvendo os elementos internos de cada faceta, construindo relações mútuas entre eles. Com esse processo, um universo de situações que requerem explicações é determinado inequivocamente pelas facetas e suas interrelações, dentro do campo de interesse da pesquisa (BILSKY, 2003).

Para o autor acima citado, a Teoria das Facetas é um procedimento que, de forma resumida, facilita expressar suposições teóricas, isso é, hipóteses, de tal forma que se pode examinar empiricamente a sua validade. Para que isso seja possível, facetas são estabelecidas, a partir de três tipos básicos: o primeiro tipo se refere à população dos sujeitos considerados na respectiva pesquisa. O segundo tipo concerne ao conteúdo das variáveis pesquisadas (estímulos, itens, perguntas). Juntas, as facetas de população e de conteúdo determinam o campo de interesse da 
pesquisa (domínio). Por fim, o terceiro tipo se refere ao universo das possíveis reações ou respostas dos sujeitos pesquisados.

A respeito da construção da sentença estruturadora geral para avaliação da agradabilidade percebida em relógios de pulso esportivos (Quadro 1), faz-se relevante mencionar que, de acordo com o que foi levantado nas considerações teóricas, foram consideradas uma faceta de contraste (baixo, médio, alto) e outra de complexidade (mínima, moderada, máxima).

Quadro 1 - Sentença estruturadora geral para a avaliação da agradabilidade percebida em relógio de pulso esportivos.

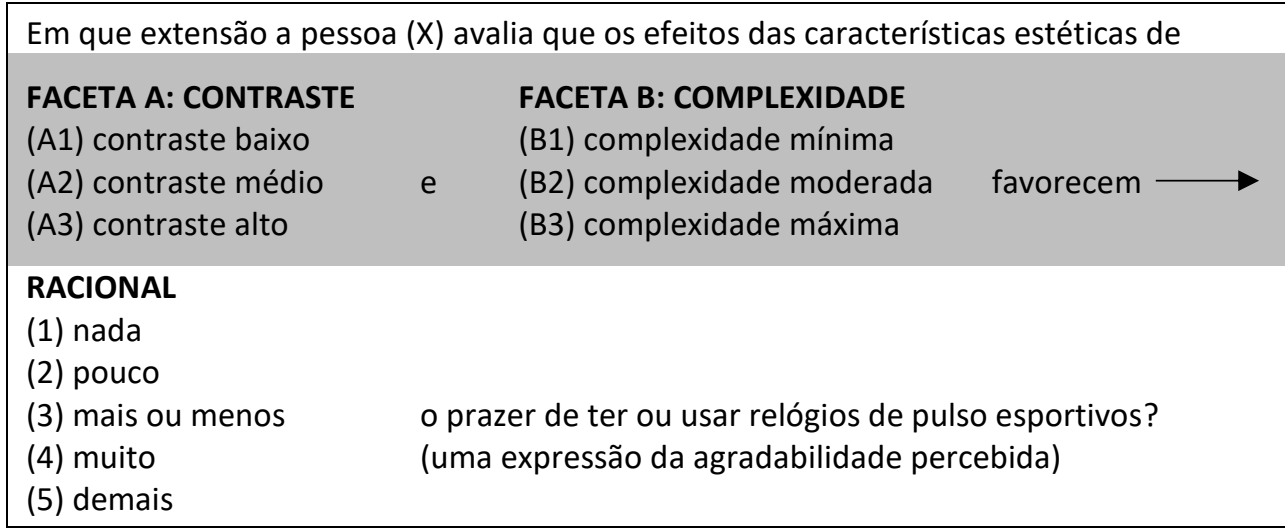

Fonte: elaborado pelos autores.

É importante estabelecer que a sentença estruturadora geral atua como uma hipótese inicial da pesquisa em desenvolvimento. Costa Filho et. al. (2016) afirma que a sentença estruturadora geral deve ser analisada em relação aos resultados empíricos encontrados, no final da pesquisa, que devem confirmar ou contestar essa estrutura. Após esse processo, as informações promovidas devem ou não servir de base para construção de uma nova sentença.

Os elementos internos das duas facetas de conteúdo - contraste e complexidade - podem ser organizados de forma semelhante a uma análise combinatória, produzindo nove diferentes conjuntos ( $A 3 \times B 3=A B 9$ ), que transmitem situações específicas a serem avaliadas (estruturantes). $A$ seta indica o mapeamento do conteúdo no conjunto de possibilidades de respostas, ou seja, cada uma dessas situações compartilha de um racional, que apresenta a variedade de cinco respostas possíveis (nada, pouco, mais ou menos, muito, demais).

Foi elaborado um questionário online, com auxílio do Formulário Google e baseado no Sistema de Classificações Múltiplas - método que consiste em solicitar informações aos participantes para classificar os mesmos elementos diversas vezes, com a finalidade de compreender suas ideias sobre o objeto de estudo -, utilizando imagens de relógios para corredores presentes no catálogo do site da empresa Netshoes. Também foi utilizado como critério de seleção dos objetos de pesquisa o gênero do público alvo, que na ocasião foi o masculino. Cabe ressaltar que não houve distinção de marcas entre os objetos, tampouco a preocupação em omiti-las dos participantes.

A seleção das imagens dos nove relógios, utilizadas como elementos de estímulo para apoiar o questionário online, está diretamente relacionada às variáveis desta pesquisa, listadas na sentença estruturadora geral para a avaliação da agradabilidade percebida em relógios de pulso 
esportivos. As imagens apresentam artefatos que se diferenciam de acordo com seus diferentes níveis de variedade de elementos estéticos presentes e o contraste entre eles. Nas imagens a seguir (Quadros 2a e 2b), estão os objetos selecionados e apresentados aos participantes, bem como a legenda para a identificação de suas características estéticas.

Quadro 2a: Relógios de pulso esportivos representando as relações entre as facetas de contraste e complexidade.

\begin{tabular}{cc}
\hline & LEGENDA \\
\hline CONTRASTE & COMPLEXIDADE \\
A1 contraste baixo & B1 complexidade mínima \\
A2 contraste médio & B2 complexidade moderada \\
A3 contraste alto & B3 complexidade máxima \\
\hline
\end{tabular}

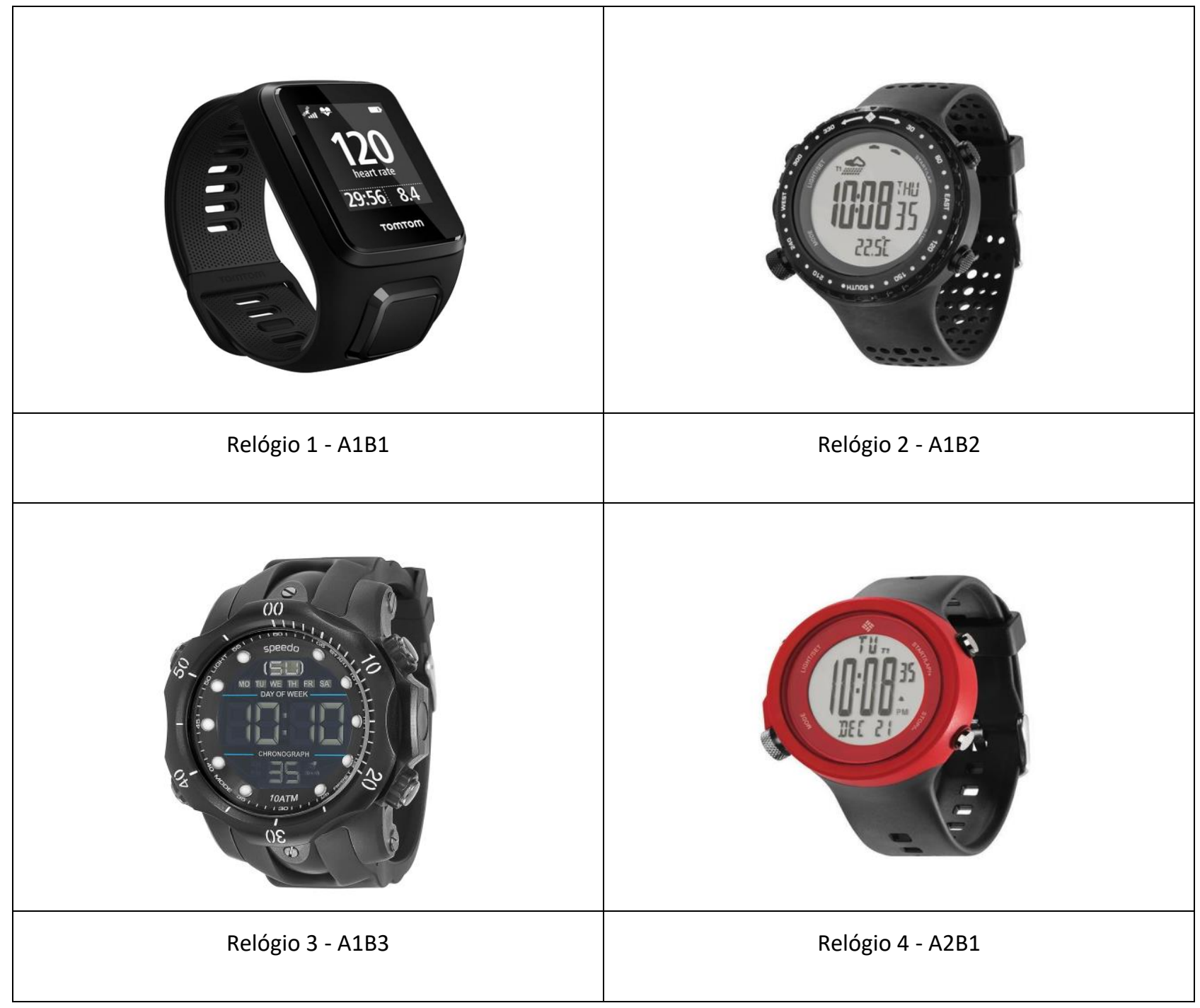

Fonte: Catálogo do site Netshoes, 2018 


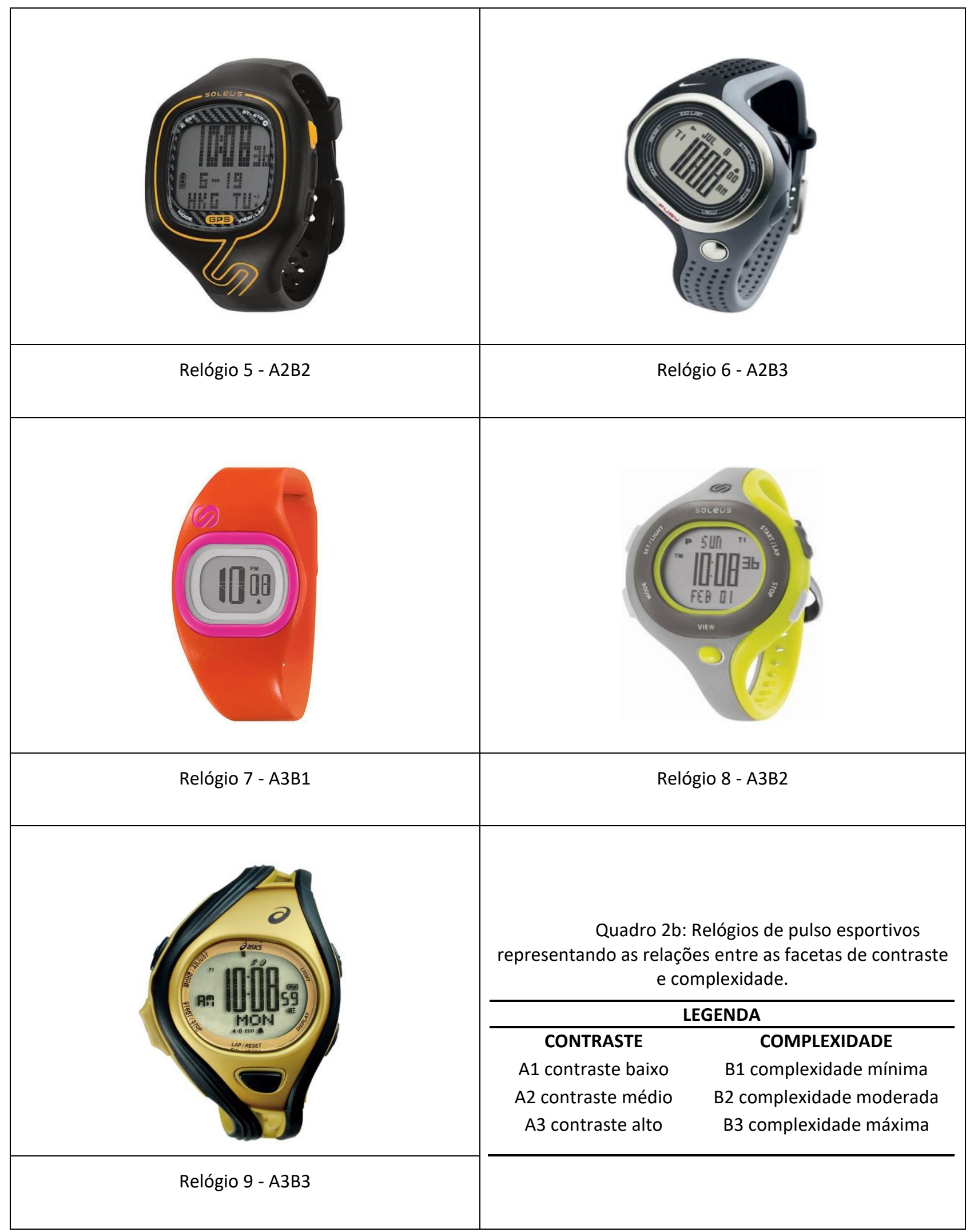

Fonte: Catálogo do site Netshoes (2018). 
Depois de selecionadas as imagens, o questionário foi finalizado, disponibilizado na Internet e seu link divulgado em grupos online de corredores de rua presentes na rede social Facebook, levando em conta a possibilidade de maior velocidade na divulgação e de atingir participantes com as características pré-definidas.

Quanto aos procedimentos de pesquisa, no sentido de resguardar o consentimento livre e desimpedido de participação, inicialmente foram esclarecidos os objetivos da pesquisa, que os dados obtidos tinham apenas fins acadêmicos e garantido o anonimato. Em seguida, os participantes do sexo masculino, após responderem perguntas como idade e formação escolar, importantes para a descrição e a caracterização do grupo, eram instruídos com a seguinte pergunta: "classifique estes relógios de pulso esportivos pelo prazer de usá-los". Tais classificações foram realizadas mediante uma escala Likert, com variações ordenadas entre 1 a 5, em que 1 significa "nada" e 5, por sua vez, "demais".

Ao final, apenas onze (11) indivíduos responderam o questionário, um número bem abaixo do esperado. Porém, como a pesquisa não tinha um caráter probabilístico ou realístico, as respostas obtidas são um indicativo importante da situação que se buscou avaliar, ficando a recomendação de trabalhos futuros que possam incrementar a amostra. Os resultados deste levantamento serão apresentados no tópico seguinte.

\section{Considerações Empíricas}

Antes de apresentar os resultados empíricos, cabe descrever e caracterizar o grupo de onze (11) indivíduos do sexo masculino, de acordo com o estabelecido como critério de exclusão para os participantes desta pesquisa, que responderam o questionário. Dentro desta perspectiva, a faixa etária desse grupo variou de 23 a 48 anos, com média de idade de 30,2 anos; e, por fim, escolaridade, em sua maioria, de ensino superior completo $(45,5 \%)$.

Tabela 1 - Escores atribuídos aos nove relógios de pulso esportivos com diferentes qualidades estéticas.

\begin{tabular}{cccccccccc}
\hline $\begin{array}{c}\text { Relógios } \\
\text { Sujeitos }\end{array}$ & A1B1 & A1B2 & A1B3 & A2B1 & A2B2 & A2B3 & A3B1 & A3B2 & A3B3 \\
\hline 01 & 5 & 3 & 3 & 3 & 3 & 4 & 1 & 2 & 1 \\
02 & 5 & 5 & 3 & 5 & 4 & 4 & 2 & 3 & 3 \\
03 & 5 & 3 & 3 & 2 & 3 & 2 & 1 & 2 & 2 \\
04 & 5 & 3 & 1 & 1 & 2 & 1 & 1 & 1 & 1 \\
05 & 5 & 5 & 5 & 5 & 5 & 2 & 1 & 5 & 3 \\
06 & 3 & 1 & 1 & 1 & 1 & 1 & 1 & 1 & 1 \\
07 & 5 & 3 & 3 & 3 & 3 & 3 & 2 & 2 & 3 \\
08 & 5 & 3 & 1 & 4 & 2 & 4 & 1 & 3 & 3 \\
09 & 5 & 3 & 3 & 4 & 3 & 2 & 1 & 1 & 1 \\
10 & 5 & 5 & 3 & 5 & 4 & 3 & 2 & 3 & 2 \\
11 & 5 & 5 & 1 & 2 & 1 & 1 & 1 & 1 & 1 \\
\hline Total & $\mathbf{5 3}$ & $\mathbf{3 9}$ & $\mathbf{2 7}$ & $\mathbf{3 5}$ & $\mathbf{3 1}$ & $\mathbf{2 7}$ & $\mathbf{1 4}$ & $\mathbf{2 4}$ & $\mathbf{2 1}$ \\
\hline
\end{tabular}

Fonte: elaborada pelos autores com base nos resultados da pesquisa. 
Os dados empíricos obtidos, relacionados à pesquisa online, estão dispostos na tabela de distribuição de frequências acima (Tabela 1). Nas linhas dessa tabela, estão listados os sujeitos participantes e os escores que cada imagem de relógios de pulso esportivos, listadas em colunas encabeçadas por seus respectivos códigos, que representam os estruturantes da situação a ser avaliada, ou seja, as relações entre as facetas de contraste e complexidade, recebeu de cada um desses participantes. Por fim, na última linha, o somatório das notas atribuídas a cada um dos elementos de estímulos utilizados nesta pesquisa (relógios de pulso esportivos). A partir desses escores, foi possível identificar qual objeto foi considerado o mais agradável, ou o que expressa o prazer de ser usado pelos usuários, assim como o seu oposto.

Os dados relacionados na tabela de distribuição das frequências (Tabela 1) mostram o efeito da coerência e da complexidade dos relógios de pulsos esportivos na agradabilidade percebida. Dessa forma, as relações entre os elementos internos das facetas estabelecidas na sentença estruturadora geral para a avaliação proposta, puderam ser testadas.

De maneira geral, os dados revelam, em parte, os efeitos esperados nas respostas avaliativas para a agradabilidade percebida, conforme predizem os postulados teóricos.

Considerando, primeiramente, os resultados para o contraste, de um modo integrado, como mostra a Tabela 1, a agradabilidade percebida é mais alta em relógios de pulso esportivos com contraste baixo (coerência alta), reduz para aqueles com contraste médio (coerência moderada), sendo menor para os relógios de pulso esportivos com contraste alto (coerência baixa). Este efeito é consistente com os resultados empíricos esperados.

Considerando, agora, os achados empíricos para a complexidade, como mostra a Tabela 1 e também de modo integrado, a agradabilidade percebida é maior em relógios de pulso esportivos menos complexos, reduz nos moderadamente complexos e é menor naqueles mais complexos.

Agora de uma maneira específica, ainda conforme a Tabela 1, o relógio de pulso de número 1 do Quadro 2a (Figura 1) com contraste baixo (coerência alta) e complexidade mínima, foi percebido como aquele que mais eleva a agradabilidade percebida. Cabe destacar que a característica de contraste baixo no objeto, conforme referenciado, ao facilitar a compreensão visual, favorece a coerência que ainda reduz a incerteza e aumenta o tom hedônico (agradabilidade ou beleza). O achado teve, portanto, relação com os postulados teóricos, que têm sido consistentemente confirmados em pesquisas.

Quanto ao fato de ser um relógio de pulso esportivo com complexidade mínima em sua figura, como também foi exposto nas considerações teóricas deste artigo, é considerado um nível de estímulo muito baixo para assegurar a agradabilidade. Pela perspectiva teórica, a agradabilidade percebida é aumentada pela complexidade moderada, uma vez que a complexidade mínima é postulada como sendo presumivelmente monótona e entediante, enquanto a alta seria caótica e estressante. Dentro dessa perspectiva, esse resultado empírico é inconsistente com aqueles postulados para a complexidade.

Cabe ainda trazer, como outra evidência empírica, que o relógio de número 7 do Quadro $2 b$ (Figura 2), relógio de pulso esportivo com contraste alto (coerência baixa) e complexidade baixa de seus elementos estéticos, foi percebido pelos participantes desta pesquisa como aquele que menos eleva o efeito da agradabilidade percebida, portanto foi julgado como sendo o menos agradável. 
Figura 1 e 2 - Relógios considerados mais agradável e menos agradável pelos participantes desta pesquisa, respectivamente.
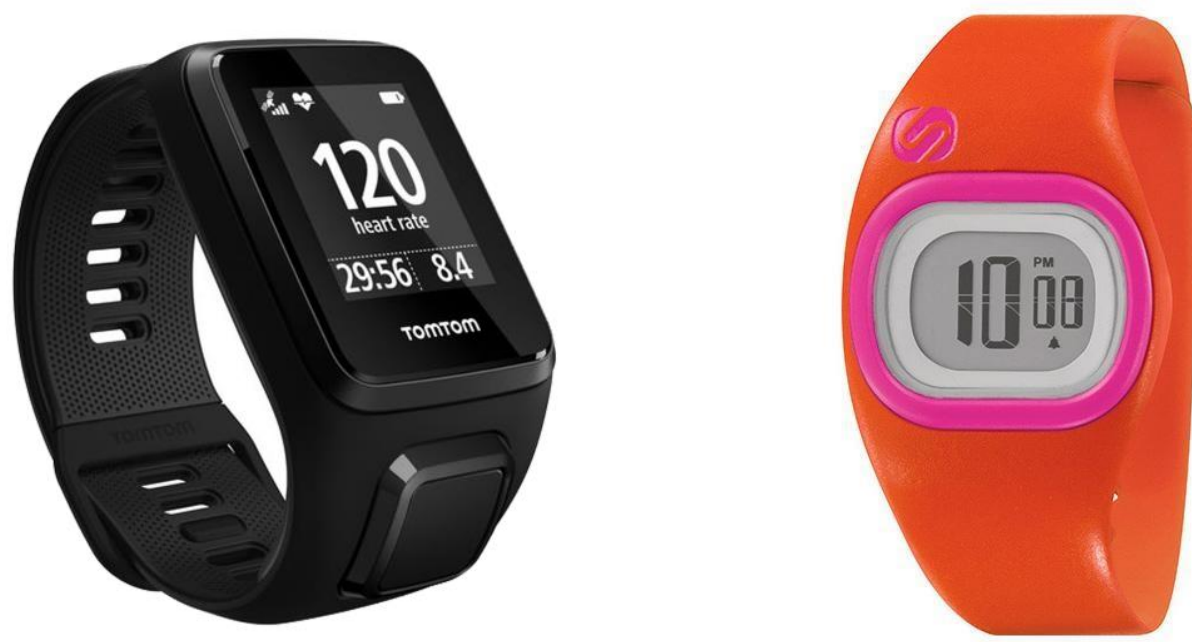

Fonte: Netshoes (2017)

\section{Conclusão}

Com base nos resultados da pesquisa, conclui-se que, para os corredores de rua abordados, o relógio de pulso esportivo que mais eleva a agradabilidade tem baixo contraste (coerência alta) e complexidade mínima, confirmando, parcialmente, o efeito de complexidade moderada estabelecida pelos postulados teóricos como sendo aquela que mais eleva a agradabilidade do objeto. Já aquele com contraste alto (coerência baixa) e complexidade baixa, representa o oposto. Na medida em que a teoria afirma que esse último efeito, de fato, não se relaciona com a agradabilidade percebida, conclui-se que, esse achado é consistente com o que prediz a teoria.

Considerando essas afirmações, em paralelo com a discussão dos resultados, conclui-se que, mesmo com o resultado final sendo satisfatório, novas pesquisas devem ser feitas dentro deste segmento, sendo também interessante a adição de novos elementos estéticos que podem também trazer dados relevantes, como, por exemplo, a delimitação de subgrupos para comparações entre os resultados.

A avaliação da agradabilidade percebida em relógios de pulso esportivos tem importância para a área do design por criar uma base objetiva para decisões projetuais, na medida em que, segundo Löbach (2001), um dos problemas principais do designer é saber de que modo deve atuar sobre o produto para provocar os efeitos desejados nos usuários.

Os resultados apurados, contudo, não devem ser tomados de maneira simplista, pois se tratam de uma compreensão para o tipo de elemento de estímulo apresentado aos respondentes nos questionários, o grupo social selecionado, e o local e a época em que a investigação foi realizada.

\section{Referências}

BERLYNE, D. E. Ends and meanings of experimental aesthetics. Canadian Journal of Psychology, 26, 1972. p 303-325. 
BILSKY, Wolfgang. A Teoria das Facetas: noções básicas. In Estudos de Psicologia, v.8, n.3, 2003. p. 357-365.

COSTA FILHO, L. L.; CIQUEIRA, A. T. S.; ROSA, S. M. de L.; CARVALHO, V. E. S. de; Efeitos da Complexidade e da Coerência na Qualidade Visual da Paisagem Midiática do Polo Caruaru. V Encontro Nacional de Ergonomia do Ambiente Construído. Rio de Janeiro - 2014.

COSTA FILHO, L. L.; OLIVEIRA, I. F.; YOKOYAMA, S. A. A qualidade percebida da paisagem midiática do comércio varejista de Caruaru. In: MONT'ALVÃO, C.; VILLAROUCO, V. (Orgs.). Um novo olhar para o projeto: 3: a ergonomia do ambiente construído. Recife: Editora UFPE, 2016.

KAPLAN, S. Perception and landscape: conceptions and misconceptions. In NASAR, Jack. (Ed.). Environmental aesthetics: theory, research, and application. New York: Cambridge University Press, 1988. p. 45-55.

O GLOBO. LEAL, G.; MAZZACARO, N.; SZPACENKOPF, M. Como as corridas de rua viraram febre na última década. Disponível em < https://oglobo.globo.com/rio/bairros/como-as-corridas-de-ruaviraram-febre-na-ultima-decada-17772322 >. Acesso em: 25 de outubro de 2017.

LÖBACH, B. Design Industrial: Bases para a configuração dos produtos industriais; tradução Freddy Van Camp - São Paulo: Blucher, 2001.

MARCONI, M. de A.; LAKATOS, E. M. Técnicas de pesquisa: planejamento e execução de pesquisas, amostragens e técnicas de pesquisas, elaboração, análise e interpretação de dados. 8. Ed. São Paulo: Atlas, 2017.

NASAR, J. L. Visual quality by design. Michigan: Haworth, Inc., 2008.

NORMAN, Donald A. Design emocional: porque adoramos (ou detestamos os objetos do dia-a-dia/ Donald A. Norman; tradução Ana Deiró - Rio de Janeiro: Rocco, 2008.

RUSSEL, James. Affective appraisals of environments. In NASAR, Jack. (Ed.). Environmental aesthetics: Theory, research, and application. New York: Cambridge University Press, 1988. p. 120129;

WOHWILL, J. F. Environmental aesthetics: The environment as a source of affect. In: ALTMANN, I.; WOHWILL, J. F. (Eds.), Human Behaviour and Environment, V. 1, 1976. p 37-86. 